\title{
Developing a Scenario Database for Product Innovation
}

\author{
Shang Hwa Hsu and Jen Wei Chang \\ Department of Industrial Engineering and Management, National Chiao Tung University, \\ 1001, Ta-Hsueh Rd, Hsinchu City 300, Taiwan ROC \\ shhsu@cc.nctu.edu.tw, jwchang.iem95g@nctu.edu.tw
}

\begin{abstract}
Introducing new product is vital for a company's survival. Scenarios have been demonstrated as a valid tool to generate product ideas from user's perspective. The purpose of this study is to develop a scenario data base for product emergence and a novel method for product idea generation. The proposed scenario database is based on a product innovation database approach that emphasizes on discovering user needs and requirements from scenarios and incorporating them into product development. It draws on the primacy of the idea itself as a driving force toward new product success.
\end{abstract}

Keywords: Scenario-based design, Database, Activity Theory, Product Idea Generation, Innovation.

\section{Introduction}

In today's complex and dynamic competitive business environment, organizations face serious challenges- new product life cycle shortened and only 20 percent of new product succeeded in the market [27]. The successful products have met consumer demands and requirements. Therefore, it is important that product innovation has to be user-oriented rather than technical-driven.

Product innovation creates competitive advantage that allows an enterprise to differentiate itself from others [1]. In order to maintain its market position in the highly competitive market, the enterprise requires a constant flow of product ideas [16] that meet market demands of usability, user centered design, and time to market.

Recent research [10] indicates that the studies of product innovation can be divided into three aspects: to emphasize the innovative people, to emphasize the process of innovation, and to emphasize the idea generation. The studies on the innovative people focus on the issue how to obtain new innovative resources from the organization's internal and external sources, including R \& D personnel, employees, suppliers, and schools or research organizations. The studies of innovation process emphasize on discovering unique or special processes that allow organizations to generate new ideas. Finally, the last one focuses on the process of product innovation that transforms creative ideas into successful new products. Among them, idea generation is considered the most important because it is closely linked to the success of products.

Scenario-based approach has been widely adopted in product innovation because scenarios can reveal the future viability of products [8] [13] [33], and reduce the probability of product failure in the market. That is, scenarios provide context of use 
that describes the characteristics of the users, the activities users engage in, and the social/ cultural, technological, as well as physical environment in which they are situated. Appropriate and useful technology can thus be developed to meet user requirements [17]. In addition, users are satisfied through the interaction experience they have with the product [24]. Therefore, scenario-based design is also related to interaction design [20].

Although the scenario-based design method is beneficial to product innovation, there are several problems needed to be resolved: First of all, the cost of scenario writing and analysis is too high. The scenario analysis or inferences will consume a lot of time and manpower. The second issue is that scenario knowledge cannot be accumulated over time. A new product may have new user groups or new product application domain so that a new product development may require designers to recollect a new set of data. The third issue is that the scenario in the present form is not readily re-usable. For one thing, each scenario is considered as a unique instance of application [27]; for another, the scenario is the lack of structure [12].

To solve this problem, this study proposed an abstract structure of scenarios based on Activity Theory. The rationale underlying the abstract structure is that different activities within scenarios may share many similar elements, such as the same context and environment, the same user characteristics, or a similar goal ... and so on. By abstracting a set of scenarios, scenario genres can be generated. The abstract structure allows designers to store, to retrieve, and to reuse scenarios in product innovation.

This scenario database not only allows businesses to quickly and cost-effectively generate product ideas, but also provides enough knowledge that can tailor the past scenarios in order to meet the demand of a specific product. This will be suitable for today's highly competitive business environment in which the capability to quickly generate a large number of new product ideas determines the core competitiveness of enterprises. This database can not only assist the creative personnel in a company to innovate but also be integrated into the enterprise's own knowledge management in product innovation, helping enterprises continue to launch successful new products.

\section{Related Research}

\subsection{Scenario Based Design}

Recently scenario design method has been widely used in product development. Carroll [7] considered scenarios could be applied to three stages in product development: analysis, design, and prototype as well as evaluate. To serve its purpose, Rolland et al. [26] argued that the scenarios used in a new product development process could be divided into three types: description (descriptive), exploration (exploratory) and interpretation (explanatory). Generally, a descriptive scenario contains the description of activities [21]. More precisely, a scenario describes an event in a situation or context [34]. However, the content of a scenario is not confined to a description of the task. Verplank[32] argued that a scenario should include the people, things, activities related to all input and output of the situation, and the environment.

In the early stage of product innovation, it is desirable to develop future (exploratory) scenarios. Campbell [6] pointed out that there are four objectives of the future 
scenarios: to envision the use of future systems, to forecast the evolution of the function of the system, to design the product attributes or product characteristics, and to simulate the use of the product. Thus, the use of future scenarios in the development process can provide a common ground for discussion among shareholders, and make sure its future use will not deviate from the user's needs. Furthermore, Schoemaker[28] argued that in a highly uncertain environment, the use of future scenario to envision and evaluate the use of future products can assist designers in product planning. Lastly, Bardram[2,3] conceived analytical scenarios as the description of what happens, when and where the event occurs, and why and how it takes place in the scenario.

Benyon et al. [4] proposed that four kinds of scenarios should be used in various stages of the design process: the user stories (user stories) for requirement analysis, the conceptual scenarios for conceptual design, and the exact scenario (concrete scenarios) and the use cases (use cases) for detail design and evaluation. Transforming from unstructured user stories into the structured use cases in the design process requires several steps: (1)abstraction of scenarios in order to define problems identify requirements and constraints confirm design constraints and regularization of the action to define the problem, demand, resulting in the conceptual model, and finally carried out physical design. He further developed a method called PACT (people, activities, contexts, technologies) to describe people, events, scenarios and use of technology in a scenario. In addition, he used UML (Unified Modeling Language) to formalize the description. In the methods proposed by Benyon, the abstraction is an important process. By the abstraction process, sets of scenarios are classified and integrated into scenario sets (scenario corpus).

\subsection{Computer Aided Idea Generation}

Computer-aided idea generation is a popular field of research in the past decades [11] Many researchers use Case Based Reasoning system, TRIZ (Theory of inventive problem solving) and other computer-based product innovation support systems to generate creative ideas [19] [30]. For example, Schuring \& Luijten [29] put forward a creative management system for accessing creative ideas. Creative Management System is also used to receive and capture, classification, and implementation of innovative ideas[5]. Wycoff [35] also maintained that a creative management system allows users to participate in creating, developing, restructuring, expanding, and measuring new possibilities of product ideas.

Nillson-Witell et al. [23] conceived creative management system as the system by which the user can browse creative ideas and further innovate new products. Dabhilkar \& Bengtsson [8] pointed out that the structure of a creative management system should enable the majority of employees to participate in creative activities and contribute to knowledge sharing. Jamali \& Boutellier [11] suggested that creative management system can collect people's ideas filter generated ideas through a collaborative process. Thus, they maintained that a creative management system is useful in enhancing the innovative capability of enterprises which is important for business growth. Riederer [25] pointed out that an innovative company, such as DaimlerChrysler, regularly use of innovative management systems to produce innovative products 
or services. The creative management system provides a structured approach to identifying the best potential for creativity.

Jamali \& Boutellier [11] argued that a creative process management system should include four functions: (a) to produce and collect ideas; (b), the initial screening of creativity; (c), creativity to improve (Refinement); (d), screening the ultimate creative. Similarly, Turrell \& Lindow [31] proposed that the creative process management system should comprise: generation, collection, development, measurement, and select the best ideas. In summary, most scholars believe that creative management system is creative and traditional methods have very different, especially the creative generation and collection process is the actual potential of new products to the creative process.

\subsection{Activity Theory}

Activity Theory (Activity Theory) is originated from 18,19-century German philosophy of Kant and Hegel, emphasizing that human development is be both active and constructive [18]. Activity Theory provides a framework of human activities and their context [14]. Activity Theory stressed the importance of environmental scenarios in the interaction between human activities (Interaction) and consciousness (Consciousness). Activity theory contended that the most appropriate unit of analysis is activities. Any activity components (Components) can be organized into a system of activities (Activity System) [9], as shown in Figure 1. Any activity involves the people (Subject), goals (Object), in the activities of the tools used in the (Tools), as well as the activities affect the overall output (Outcome) action (Action) and operation (Operation) [22]. According to an extended perspective proposed by Engestrom, in addition to the above-mentioned

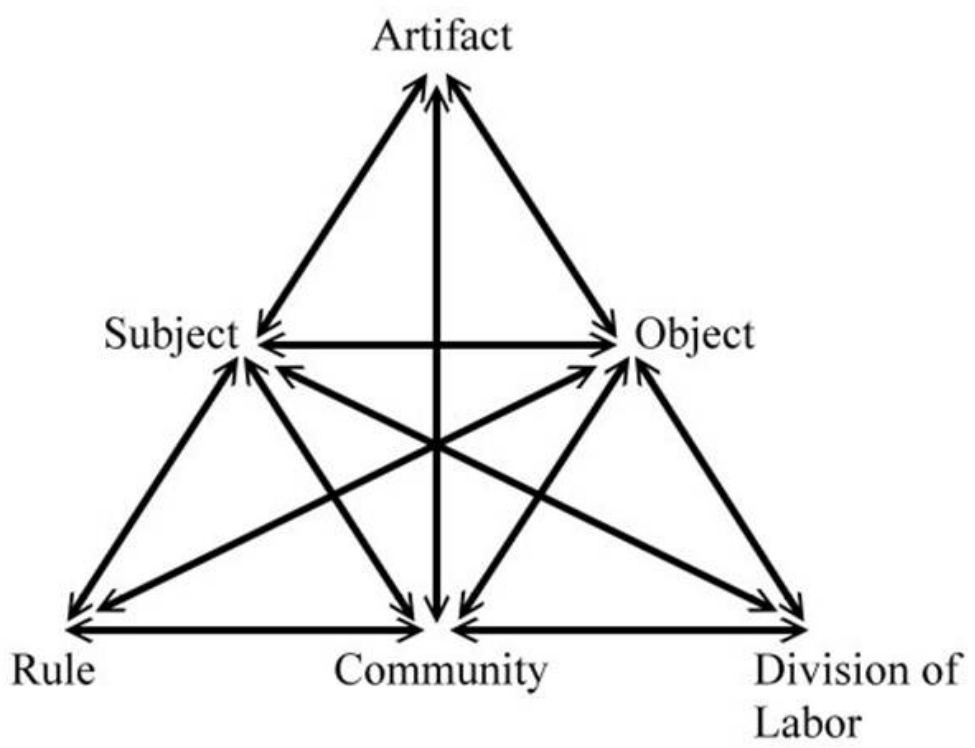

Fig. 1. The activities of the theoretical framework (Adapted from [9]) 
components, the norms (Rules), Community (Community) and the activities of the division (Division of Labor) should be also included. Goal is the entity that activities pursued for or a product of human mind. It can be regarded as a kind of motivation (Motivation), a problem space (Problem Space), or the output is the result of achievement of objectives. The relation between activities and objects are mediated by tools.

Kaenampornpan \& O'Neill [15] suggested that the Activities Theory is helpful in identifying both key components of human activities and their relationships. It is suitable for classifying scenarios because it has several important features: (a) the framework of activities prescribed by Activity Theory can serve as a standard format to describe activities in a scenario; (b), Activity Theory relate the link between individual activities and social activities; (c), Activity Theory provides concepts of an intermediary; (d), Activity Theory models the components of human activities and the relationships between components.

\section{Methods}

Scenario database is a classification system of product usage scenarios. The entire development process of scenario database consists of three steps: (1) to collect scenarios, (2) to decompose scenarios into elements and then abstract to scenario genres, (3) to develop the data base, and (4)to design the functionality of the database.

\subsection{Collecting Scenarios}

Scenarios for an application domain (e.g., transportation) were collected. Scenario may be collected from the potential customers or end-users, designers, engineers, and marketing personnel. The methods used to collect scenarios include interviews, surveys, logs, videos, and ethnography. Typically, the content of a scenario contains a series of activities and events through which a user to achieve the final goal. The scenarios allow designers to envision user s' problems in their daily lives.

In order to ensure and validate the quality of every collected scenario, each scenario has to be examined through a scenario analysis. The main aim of scenarios analysis is to make sure the important elements of a scenario, such as the user, activities, the use of the tools, the people around, and the environment, are available in the scenario. The scenarios were analyzed in terms of $5 \mathrm{~W} 1 \mathrm{H}$; that is, events (What is happening?), around there who (Who are the roles in scenarios?), wherever they occur (Where the scenarios take place?), when (When did the scenarios happen?), Why (Why did there scenarios happen?), and how the scenario is carried out (How did the scenarios proceed?).

\subsection{The Decomposition-Abstraction Process of Scenarios}

This part aims to decompose scenarios into elements and then abstract the higherlevel concepts of the elements. The abstraction of higher-level concepts can yield generalized sets of scenarios (i.e., scenario genres). 


\section{- Identify the activities in Scenarios}

Scenarios may cover several ongoing activities. The decomposition process should cover all the ongoing activities and their relationships. Since activity is goal-directed, abstraction of activities is to identify the activity group that shares the same goal. Accordingly, we have identify goals of activities.

- Define the Subject, Object, and Community in Scenarios

The subject attempts to achieve a goal by carrying out activities. In performing an activity, a subject (i.e., a user) has to exploit the object available to him/her. The subject in activities can be an individual or a group of people (i.e., a community or an organization). The object can not only serve as a mediator between subject and goal but also relate people within a community. A community includes the physical context (such as time, place, and weather) and social context (such as group dynamics). Therefore, in this step, we need to identify the subject, the objects, and the community in scenarios and then categorize them into subject types, object types, and community types.

\section{- Analyze Users Motives in Scenarios}

Users are driven by their motives (such as: social needs) in carrying out activities, and finally reached its desired goal (such as: friends invited to participate in the party). Analysis of the motives can allow designers to discover users' explicit and implicit needs. User needs analysis can reveal the functional and emotional requirements of the product.

\section{- Decompose Activities in Scenarios}

Activity has a hierarchical structure. It is a coordinated, integrated set of actions. Actions are targeted toward a specific goal, and are achieved through operations. Conditions will control what operations will be taken, and conditions and goals together will determine the use of the product. Based on the activity-actions-operations hierarchy and activity flow pattern, a use model is then developed to describe the mapping between product functions and activity flow. Accordingly, the decomposition of activities can lead to the mapping between functions and actions.

- Analyze the rules that govern the interaction among subjects in a community

The rules exist between the subject and the community. The rules make the subject and the community to sustain their activities. Rules may be the social rules, such as laws, customs. Analysis of the rule can led to the identification of social interactions.

- Analysis of the division of labor between Community and Object

In order for achieving a common goal, members in the community have to play certain roles and assume proper duties. Therefore, task activities have to be divided and allocated to appropriate people. This division of labor may prescribe the roles, such as the leader or be leaded, manage or be managed, and the relationship between different roles. The division of labor describes task allocation and allows designers to identify the need for team collaboration.

\subsection{Develop the Database Structure}

Statistical analysis is performed to establish the relationships among subject types, activity types, motives, social interaction, and team collaboration. This constitutes a 
database of user requirements. User requirements can then be mapped to functional requirements and

\subsection{Design Scenarios Database's Functionality}

This study designs the scenario database functions through case-based reasoning (CBR) mechanism. The concept of CBR is originated from psychology and became the most popular AI paradigm in idea generation domain. The theorem of CBR is to retrieve similar cases to solve the problem. $\mathrm{CBR}$ requires exploration of the analogical memory rather than searching it for a specific analogy. Based on CBR, the functions of the scenario database are identified as below:

- Retrieve: to search for extract the most similar scenario case, or a number of high similarity candidate in order to solve the problems.

- Re-use: to reuse the information and knowledge contained in the scenario case.

- Revise: to modify and update the information of scenario case.

- Retain: to save and add scenario case in scenario database.

By using these functions, innovation activities can be accomplished by retrieving similar scenarios cases.

\section{Conclusion}

Scenario Design is a widely used method in product innovation process. Scenarios describe the process and the context that people perform their activities. Through the understanding of the activities, designers can envision the demand. However, the validity of scenario-based design is questioned by opponents because only a limited number of scenarios were employed in the design. Therefore, the purpose of this study is to develop a scenario database that consists of a set of scenarios encompasses a wide range of user problems. As Nardi [21] points out that activity theory provides a framework that can tie the loosely connected elements of a scenario into a welldefined structure. Based on Activity Theory, the elements in scenarios were abstracted into generalized types and, consequently, the information in the scenario can be reused and accumulated over time.

In the database scenarios, case-based reasoning is employed as an inference mechanism for applying the database for a new product development. Case-based reasoning is a simulation of human problem-solving mechanism, with its emphasis on experience and memory through the past to solve new problems. It also has implied learning function. The construction of creative management system not only allows experts to collect, modify, and delete a scenario in the database, but helps members of the organization learn from experts how to present and solve a design problem. Through the use of this creative management system, inter-departmental co-operation (such as design and manufacturing sector) can be enhanced and so does organizational creativity.

\section{References}

1. Alves, J., Marques, M., Saur, I., Marques, P.: Building creative ideas for successful new product development. In: 9th European Conference on Creativity and Innovation (ECCI9): 'Transformations', September 4-7 (2005) 
2. Bardram, J.: Scenario-based design of cooperative systems. In: Proceedings of COOP 1998, Cannes, France (1998)

3. Bardram, J.: Scenario-based Design of Cooperative Systems: Re-designing a Hospital Information System in Denmark. In: Group Decision and Negotiation, vol. 9, pp. 237-250. Kluwer Academic Publishers, Dordrecht (2000)

4. Benyon, D., Turner, P., Turner, S.: Designing interactive systems: People, activities, contexts, technologies. Addison Wesley, Boston (2005)

5. Bessant, J., Caffyn, S., Gallagher, M.: An evolutionary model of continuous improvement behavior. Technovation, pp. 67-77 (2001)

6. Campbell, R.L.: Will the real scenario please stand up? SIGCHI, Bull. 24(2), 6-8 (1992)

7. Carroll, J.M.: Scenario-based design: Envisioning work and technology in system development. John Wiley \& Sons, New York (1995)

8. Dabhilkar, D., Bengtsson, L.: Continuous improvement capability in the Swedish engineering industry. International Journal of Technology Management 37(3-4), 272-289 (2007)

9. Engestrom, Y.: Learning by expanding. Orienta-Konsultit Oy, Helsinki (1987)

10. Goldenberg, J., Mazursky, D.: Creativity in product innovation. Cambridge University Press, Cambridge (2002)

11. Jamali, N., Boutellier, R.: Idea Management System: Process. Continuous-innovation.net (2006),

http: / /www. continuous-innovation.net/Members_only/Publications / papers_7th/jamali_boutellier_cinet2006.pdf

12. Jarke, M., Bui, X.T., Carroll, J.M.: Scenario management: An interdisciplinary approach. Requirements Engineering Journal 3(3/4), 154-173 (1998)

13. Joe, P.: Scenarios as an essential tool: stories for success. Innovation Quar. J. Ind. Des. Soc. Am, 20-23 (1997)

14. Jonassen, D.H., Murphy, M.: Activity theory as a framework for designing constructivist learning environments. Annual meeting of the Association for Educational Communications and Technology 47(1), 61-79 (1998)

15. Kaenampornpan, M., O’Neill, E.: An Integrated Context Model: Bringing Activity to Context. In: Proceedings of UbiComp 2004, Tokyo, Japan (2004)

16. Kao, J.: Jamming: The Art and Discipline of Corporate Ceativity. Harper Business (Creativity), 224 (1997)

17. Kreifeldt, J.G.: Guarding snowblowers. In: Interface 1987 Proceedings, Human Implications of Product Design. Human Factors Society, Consumer Products Technical Group, Santa Monica, CA, pp. 259-304 (1987)

18. Kuutti, K.: Activity theory as a potential framework for human-computer interaction research. In: Nardi, B. (ed.) Context and consciousness: Activity theory and human computer interaction, pp. 17-44. MIT Press, Cambridge (1996)

19. Maher, M.L., Balachandran, M., Zhang, D.M.: Case-Based Reasoning in Design. Lawremce Erlbaum, Hillsdale (1995)

20. Moggridges, B.: Designing Interactions. MIT Press, Cambridge (2007)

21. Nardi, B.: The use of scenarios in design. SIGCHI Bulletin 24(4), 13-14 (1992)

22. Nardi, B.: Context and consciousness: Activity theory and human computer interaction. MIT Press, Cambridge (1997a)

23. Nilsson-Witell, L., Antoni, M., Dahlgaard, J.J.: Continuous Improvement in Product Development; Improvement Programs and Quality Principles. International Journal of Quality and Reliability Management 22(8), 753-768 (2005)

24. Norman, D.A.: The psychology of everyday things. Basic Books, New York (1998) 
25. Riederer, J.P., Baier, M., Graefe, G.: Innovation Management-An Overview and some Best Practices. C-LAB Report 4(3) (2005)

26. Rolland, C., Ben, A., Cauvet, C., Ralyté, J., Sutcliffe, A., Maiden, N.A.M., Jarke, M., Haumer, P., Pohl, K., Dubois, E., Heymans, P.: A Proposal for a Scenario Classification Framework. Requirements Eng. J. 3(1), 23-47 (1998)

27. Rosson, M., Carroll, J.M.: Scenario based design. The Human-Computer Interaction Handbook: Fundamentals (2002)

28. Schoemaker, P.J.H.: Scenario planning: A tool for strategic thinking. Sloan management review 36(2), 25-40 (1995)

29. Schuring, R., Luijten, H.: Re-inventing suggestion schemes for continuous improvement, Continuous Improvement - From Idea to Reality. Twente University Press, University of Twente (1998)

30. Sun, Y., Lai, C.: A conceptual design system based on human-machine integrates intelligence. Journal of Information \& Computational Science 1(2), 313-318 (2004)

31. Turrell, M., Lindow, Y.: The Innovation Pipeline. Imaginatik Research White Paper (March 2003)

32. Verplank, B., Fulton, J., Black, A., Moggridge, B.: Observatin and Invention- Use of Scenarios in Interaction Design. Tutorial notes (1993)

33. Welker, K., Sanders, E.B.-N., Couch, J.S.: Design scenarios to understand the user. Innovation Quart. J. Ind. Des. Soc. Am, 24-27 (1997)

34. Wright, P.: What's in a scenario? SIGCHI Bulletin 24(4), 11 (1992)

35. Wycoff, J.: The Big Ten Innovation Killers and How to Keep Your Innovation System Alive and Well. Innovation Network (2004) 